\title{
Improving the quality of reproductive health care: How much does it cost?
}

Laura Raney

Stephanie Joyce

Population Council

John Townsend

Population Council

Follow this and additional works at: https://knowledgecommons.popcouncil.org/departments_sbsr-rh How does access to this work benefit you? Let us know!

\section{Recommended Citation}

Raney, Laura, Stephanie Joyce, and John Townsend. 2003. "Improving the quality of reproductive health care: How much does it cost?" New Perspectives on Quality of Care Brief. Washington, DC: Population Reference Bureau and Population Council. 


\title{
Improving the Quality of Reproductive Health Care: How Much Does It Cost?
}

\author{
Laura Raney, Stephanie Joyce, and John W. Townsend
}

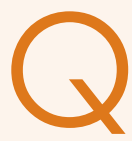
uality care for clients should be the focus of a family planning and reproductive health program. But can programs afford it? There is no simple answer. The multiple dimensions of quality of care make it more difficult to identify and measure affordable improvements in service delivery. Calculating program costs is challenging, and different methods of determining costs can lead to widely varying estimates (Janowitz and Bratt 1992). The critical elements of a quality service may vary from program to programand from one perspective to another. Determining how much quality costs is a challenge, but it is both possible and important for programs' sustainability.

There are few studies that quantify the cost and cost effectiveness of providing high-quality reproductive health care. This brief focuses on various aspects of costs and examines information about the cost of improving quality (as opposed to the cost of quality of care in general), then outlines some ways to improve quality while containing costs.

Quality, access, and cost are interrelated program elements, and a change in one element affects the others. Given their finite resources, programs may face difficult choices as they attempt to find the appropriate balance. Ideally, decisions about quality should be the result of a dialogue among key stakeholders: policymakers, providers, and clients. Each program has to decide what standard of quality is appropriate to apply considering its situation, its resources, and the needs and perceptions of the population it is meant to serve.

This policy brief, part of the New Perspectives on Quality of Care series, uses the framework developed by the U.S. Agency for International Development's Maximizing Access and Quality (MAQ) initiative.

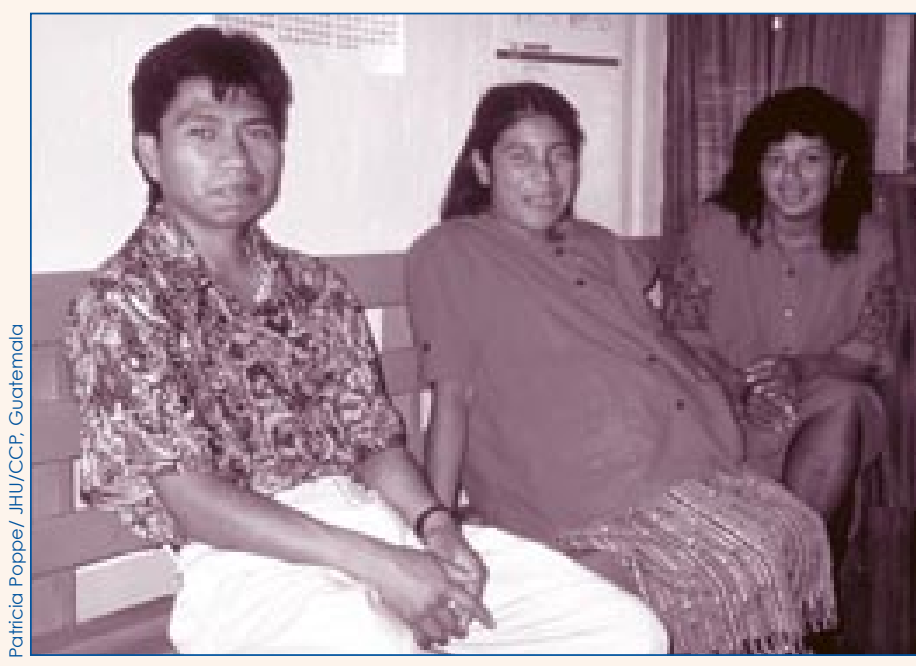

Improving quality of care can save money for both programs and clients.

\section{Why Invest in Quality?}

Quality has many dimensions. From an ethical standpoint, program managers need to satisfy clients' rights to obtain competent, compassionate, high-quality care. Perceptions of quality can be subjective. Clients tend to value the appearance of the service setting, privacy, respectful treatment, and convenience, while providers emphasize facility environment, program infrastructure, and workload (Bruce 1990; Jain 1989; Khan et al. 1999; see also the other briefs in this series).

Quality services have many benefits. Improvements in quality can save money for both programs and clients, and quality services may attract more clients while reinforcing programs' efficiency and sustainability. Moreover, providing appropriate levels of quality can prevent the longer-term - often hidden - costs associated with poor care. For example, a client who receives inadequate counseling may not use contraceptives correctly and may experience an 
unwanted pregnancy or a preventable infection. Managers should view the costs of providing quality care as investments in the future wellbeing of both clients and programs.

Quality improvements may pay for themselves in the long run by attracting new clients or leading to economies of scale, but few changes are entirely without costs. Costs may involve staff and managers, requiring different uses of employees' time, or they may be financial, requiring that the program invest in research or training. Some quality improvements, such as purchases of high-tech equipment, can be expensive, but even changes that do not involve substantial monetary investment, such as encouraging staff to greet clients warmly, can be valuable. In most cases, changes leading to quality improvement must receive

\section{Box 1}

\section{Definitions of Costs}

The different types of costs defined here may overlap; for example, staff salaries are both direct costs and recurrent costs. The purpose of the costing exercise will help determine which definitions are used.

Direct costs: costs specifically identified with a service or product, such as staff salaries or the price of contraceptive supplies.

Indirect costs: costs that support service delivery, such as managers' salaries or the costs of monitoring care.

Recurrent costs: costs associated with inputs that will be consumed in one year or less, such as salaries and certain medical supplies.

Capital costs: costs or resources that have a life expectancy of more than one year, such as buildings.

Total costs: the sum of recurrent and capital costs.

Average or unit cost: the total cost of a service (such as an antenatal care visit) divided by the number of units of service provided.

Marginal cost: the cost of providing one more unit of service, such as seeing one additional client.

Fixed costs: costs that cannot be changed in the short term (up to one year), such as staff salaries.

Variable costs: costs that can be changed in the short term, such as costs associated with the number of supervisory visits.

SOURCES: B. Janowitz, et al., Issues in the Financing of Family Planning Services in SubSaharan Africa (1999); and A. Yazbeck, "But How Much Does It Cost?" (1999). support and continued attention from supervisors and management to ensure their sustainability.

\section{Opportunities for Improving Cost Effectiveness and Quality}

Various definitions of costs are given in Box 1 .

Studies of service costs yield varying estimates depending on such factors as the purpose of the costing exercise (pricing a specific service versus costing an entire program), type of service, service setting, data available, and method of calculation used; for example, some studies include indirect costs such as the management of health services and the costs to clients (Mumford et al. 1998). Obtaining a clear view of a program's cost structure and financial constraints is the first step in determining how much services cost and how to pay for quality improvements. Many program managers use the cost analysis tools described in Box 2 to help assess the advantages of existing or proposed innovations, which might include improving the clinical setting, increasing service efficiency, combining or integrating services, enhancing client screening, or adding more appropriate services.

\section{Improve the Clinic Setting and the Flow of Clients}

Making the clinic setting more welcoming and convenient for clients is among the quality improvements that can improve efficiency and increase client satisfaction at minimal cost. At one site in rural Guatemala, for example, clinic staff and selected clients identified several lowcost physical improvements, including repainting the clinic (using supplies donated by the local mayor) and adding signs to better identify the clinic, that clients felt would improve their experience at the clinic. Clients appreciated these small changes, which contributed to the community's sense of ownership of the clinic (Burkhart and Solórzano 1999).

Long waiting times inconvenience clients; one study of 26 clinics in Latin America found that clients waited an average of 80 minutes for initial visits. Detailed analysis of client flow has helped cut waiting times by as much as 50 
percent in many of these settings (Berrio et al. 1990). Such changes can allow facilities to treat more clients, a factor that could be particularly relevant for programs that rely heavily on user fees.

Health center staff at the rural clinic in Guatemala also examined clinic procedures to determine how they could make services more client-friendly. They analyzed how patients moved through the center and found that simple changes, including eliminating time-consuming preconsultation steps, adding a "short route" for quick services such as immunizations, and modifying clinic schedules to provide a wide range of services every day, were easily made. As a result, most clients spent significantly less time in the health center: 93 percent of clients spent less than one hour at the clinic at each visit (Burkhart and Solórzano 1999).

Increase Service Efficiency

\section{Improve Use of Staff Time}

Studies have shown that providers often use a substantial amount of their time unproductively. Janowitz et al. (2001) summarize four studies in which observers recorded staff activities every three to five minutes: On an average day, staff in Ecuador spent 56 percent of their time with clients; staff in Bangladesh spent only 30 percent with clients. Some of the remaining time was spent on administrative tasks, including preparing work areas and attending meetings, but providers also spent time on personal business and breaks. If resources such as staff are underutilized, the marginal cost of seeing additional clients is close to zero. By rearranging the workday or scheduling visits more efficiently, facilities could see more clients, further improving the use of existing staff and resources. The number of visits to the rural clinic in Guatemala that made such changes nearly doubled, from 522 to 1,039 visits per month, with no change in clinic hours or staff (Burkhart and Solórzano 1999).

Programs can also improve their quality by focusing on the efficiency of specific provider duties. León et al. (2001) showed that providers of family planning counseling spent too much time describing all available methods and failed

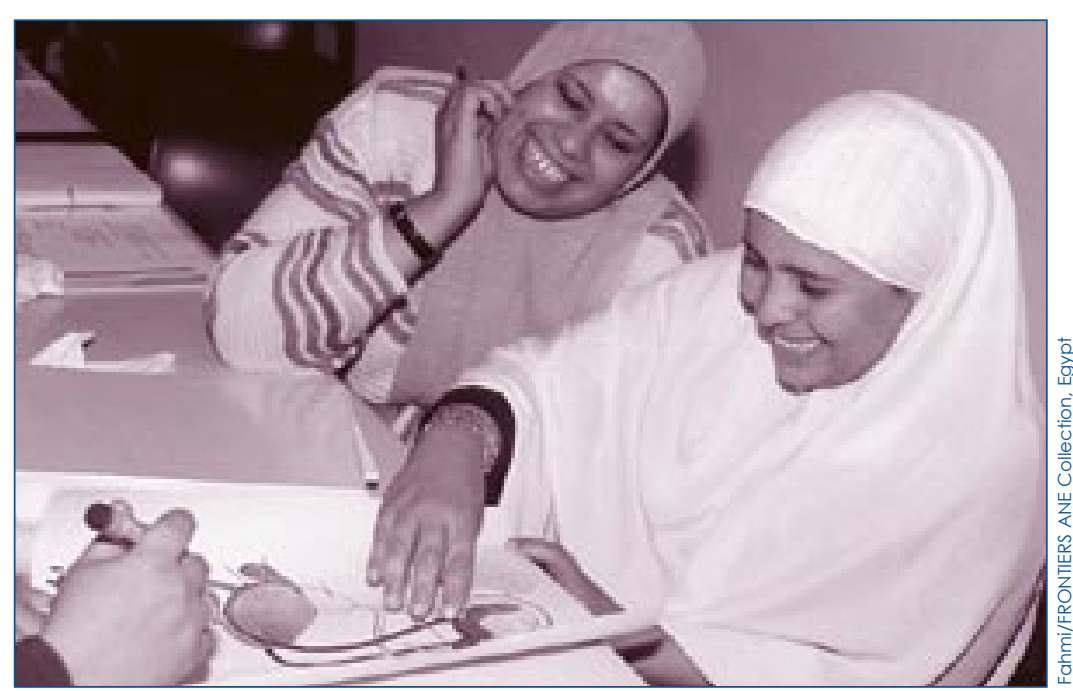

Providing more effective counseling is an important way to improve quality of care without substantially increasing costs. Checklists, flip charts, and other job aids can help providers remember to include the essential points during counseling sessions.

Box 2

\section{Economic Analysis: A Critical Tool for Planning Quality Improvements}

Economic analysis can be a valuable tool for decisionmakers at various levels, from politicians responsible for defining national family planning policy to managers who are assessing services at an individual service site. Cost-effectiveness analysis and costbenefit analysis are two powerful tools often used by policymakers and program managers.

Cost-effectiveness analysis assesses the relative efficiency of alternative policies in situations where it is impractical to assign a monetary value to the policy's objective, such as improving health status. The cost effectiveness of a service or program is measured in terms of quantifiable outputs, such as the number of contraceptive users treated or HIV screening tests conducted. Costeffectiveness analysis enables program managers to identify the least expensive way to meet a clearly defined objective.

Cost-benefit analysis compares the costs and effects of two or more types of alternative courses of action, where costs and benefits are measured in monetary terms; that is, where a monetary value is attached to each of the social benefits resulting from the action. It allows managers to compare the monetary value of a policy's social benefits (such as days free from illness) to its costs.

SOURCE: J. Knowles and J. Berman, "Economic Evaluation of Family Planning and Reproductive Health Policies” (2000).

to provide sufficient information about the use and side effects of the method chosen by the client. Further research showed that the quality of counseling improved significantly when providers used an alternative counseling model 
Table 1

Changes in Cost per Additional Reproductive Health Service in Guatemala and Mexico

\begin{tabular}{ccc}
$\begin{array}{c}\text { Number of Services } \\
\text { Provided During Visit }\end{array}$ & \multicolumn{2}{c}{ Cost per Service (\$) } \\
\hline 1 & $\$ 2.41$ & $\$ 3.21$ \\
2 & 1.11 & 2.05 \\
3 & 1.27 & 1.73 \\
4 & $\mathrm{n} / \mathrm{a}$ & 1.25 \\
Average Cost & 2.29 & 2.79 \\
\hline
\end{tabular}

$\mathrm{n} / \mathrm{a}=$ Not available.

Note: Cost per service includes personnel costs and materials.

SOURCE: R. Vernon and J. Foreit, "In-Reach for Providing More Preventive Reproductive Health Care" (1998). nization in combination with its reproductive health outreach services. An experiment in two areas of rural Bangladesh indicated that this combination was more cost effective than merely offering the services at particular service delivery points (Levin et al. 1999).

Integrating services can reduce the cost of providing care to the same clients on multiple visits and may be more convenient for the clients. For instance, follow-up care for intrauterine devices (IUDs) might be combined with Pap smears and screening for reproductive tract infections; a study in Zimbabwe found that providing all three services during one visit cost 40 percent what three separate visits cost (Mitchell et al. 1999).

A review of reproductive health services in Guatemala showed that because clients tend to seek only one service during clinic visits-and providers tend to furnish only that servicemany opportunities to provide a wider range of services are lost (Vernon et al. 1997). In the long term, giving clients information about other available services can reduce the costs facing both clients and the program. Cost analyses in Guatemala and Mexico have shown that providing multiple services during a given visit is more cost effective than requiring the client to return for several visits (see Table 1). The cost of providing additional services generally decreases with each additional preventive service provided during a single visit, creating potential cost savings for the client and the program (Vernon and Foreit 1998).

\section{Eliminate Unnecessary Procedures}

In some settings, inappropriate policies and protocols intended to protect clients may actually constitute a barrier to effective services. These barriers (discussed elsewhere in this series) may adversely affect quality by discouraging clients from seeking services, impeding providers' effectiveness, and burdening the health care system with unnecessary costs.

In some settings, policies include requirements that impose high costs on the system without benefiting clients significantly. Stanback et al. (1994) investigated the cost effectiveness of mandatory laboratory testing

\section{Combine or Integrate Services}

Combining or integrating existing services can allow programs to use resources more effectively and can provide additional benefits to clients. For instance, a clinic might offer immu- 
for first-time users of the pill in Dakar, Senegal. The test found that less than 3 percent of women tested were likely to suffer complications from using the pill, while each test cost between $\$ 55$ and $\$ 216$, almost 100 times the per capita health expenditure. Given how unreliable and expensive the tests are and how potentially risky an unwanted pregnancy could be, eliminating the requirement was a costeffective way to improve quality.

Similarly, many health care systems require follow-up visits for specific family planning methods, such as IUDs, but the revisits can quickly overload the system. A study in Ecuador showed that 29 percent of the women who returned to their providers after receiving IUDs would have done so without prompting; less than 1 percent of the remainder required treatment or removal of the device. Replacing mandatory visits with guidelines about when users should seek medical help could substantially reduce revisits and improve the care for new acceptors and women who do experience problems (Janowitz et al. 1994).

\section{Add Appropriate Cost-Effective Services}

Adding carefully selected services can also improve both cost and quality. In urban clinics, ultrasound services for prenatal and maternal care may be a cost-effective addition. The Centro Médico de Orientación y Planificación Familiar (CEMOPLAF), a women's health nongovernmental organization, studied the addition of ultrasound services in Quito, Ecuador, projecting start-up costs, operating costs (the expenditures needed to provide services), and client demand for ultrasound services, and taking into account the prices charged by competitors. CEMOPLAF found that providing the ultrasound machines and related training in only four of the 19 clinics initially interested in adding such services would be the most costeffective approach (Bratt et al. 1998).

Studies in multiple settings have demonstrated that improving postabortion care (PAC) - defined in these studies as emergency treatment, family planning services and referrals, and links to other reproductive health services following spontaneous or induced
Table 2

\section{Cost Changes Following Improvements to Postabortion Care Services in Selected Countries}

\begin{tabular}{lccc} 
Country & $\begin{array}{c}\text { Pre-Intervention } \\
\text { Cost (\$) }\end{array}$ & $\begin{array}{c}\text { Post-Intervention } \\
\text { Cost (\$) }\end{array}$ & $\begin{array}{c}\text { Percentage } \\
\text { Change }\end{array}$ \\
\hline Burkina Faso & $\$ 34$ & $\$ 15$ & -56 \\
Egypt & 14 & 16 & 14 \\
Mexico & 264 & 180 & -32 \\
Peru & 119 & 45 & -62 \\
Senegal & 61 & 46 & -25 \\
\hline
\end{tabular}

SOURCES: Burkina Faso Ministry of Health, Introduction of Emergency Medical Treatment and Family Planning Services for Women With Complications From Abortion in Burkina Faso (1998); L. Nawar et al., "Cost Analysis of Postabortion Care in Egypt" (1999); J. Fuentes Velásquez et al., A Comparison of Three Models of Postabortion Care in Mexico (1998); J. Benson et al., Improving Quality and Lowering Costs in an Integrated Postabortion Care Model in Peru (1998); and Centre de Formation et de Recherche en Santé de la Reproduction et al., Introduction des Soins Obstetricaux d'Urgence et de la Planification Familiale Pour les Patientes Presentant des Complications Liées a un Avortement Incomplet (1998).

abortion-led to improvements in both quality and cost effectiveness. Comparison of changes in costs following interventions to improve PAC in five countries (see Table 2) showed substantial reductions in four of the countries, due to more-efficient use of staff time and reduced hospital stays. But improved services are not always less expensive: In Egypt, reorganization of PAC involved raising standards of care, including improvements in pain control, provision of counseling, and closer adherence to infection-control standards, leading to modest increases in cost (Huntington 2000).

In areas where sexually transmitted infections (STIs), including HIV/AIDS, are prevalent, the devastating consequences of undetected or untreated infections make it critical that program managers consider alternatives for screening and managing these infections. Such alternatives include laboratory testing and treatment, routine treatment of all clients, treatment of specific symptoms (syndromic management), no treatment but referral, or a combination of approaches. Although few studies have analyzed the costs of STI services within the family planning context, one model of STI screening and case management in India showed that donors and managers often underestimate the costs of adding these 


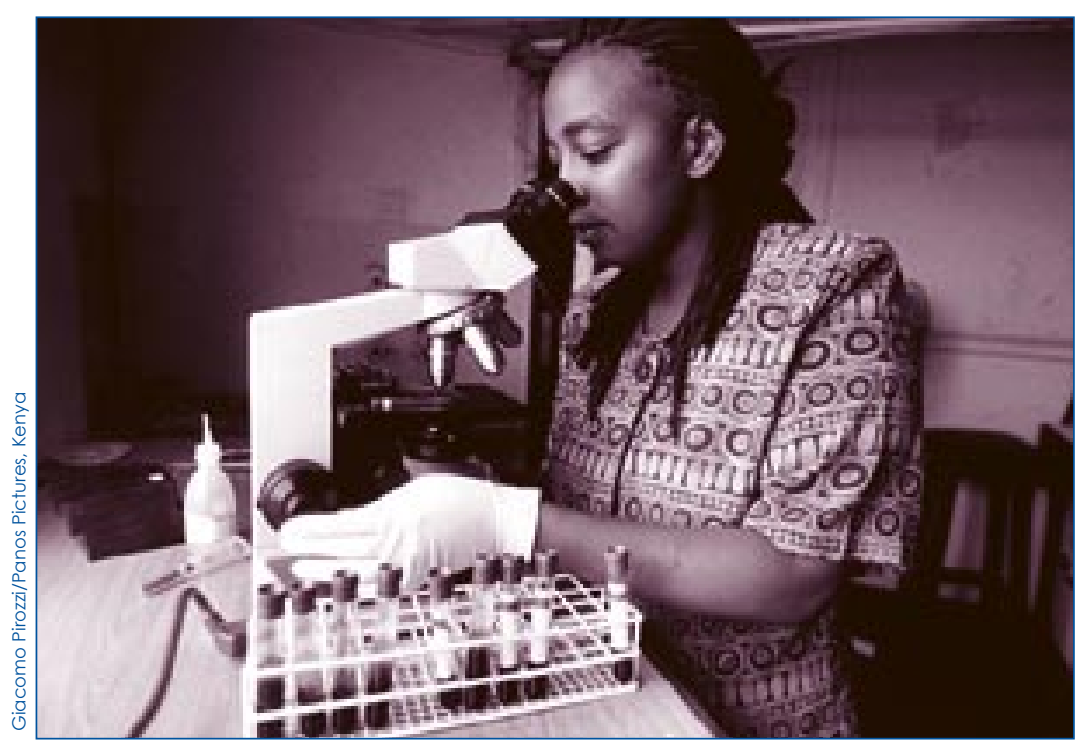

Sexually transmitted infections can have devastating consequences if not detected and treated. Providers should consider the risk profile and prevalence rates of their target population when determining how to allocate resources for STI services.
Improve Service Management

\section{Enhance Institutional Support to Providers}

Programs need to ensure that providers receive the support they need to function effectively and improve or maintain the quality of their work. Numerous measures for improving institutional support can enhance quality at reasonable cost. Managers who want to improve the quality of the services they offer should consider specific areas. For example, alternative approaches to supervision can reduce costs without diminishing quality (see Policy Brief 3, "Providers and Quality of Care").

Another option for enhancing institutional support is improving logistics. Ensuring the reliable availability of contraceptives and reproductive health supplies is an essential part of quality reproductive health care, especially from the clients' point of view. Many family planning clients in Lesotho who stopped using contraceptives said that they had done so because their preferred method or brand was periodically not available (Bertrand 1991). Improving logistics can also cut program costs and prevent waste. Managers in Kenya used a new tracking and distribution system to improve their estimates of demand and their use of funds: Using money originally projected to provide STI kits for 143 sites for one year, they were able to provide the kits to more than 500 sites over two years (Venugopal 2002).

Efficient training, including instruction in new skills and refresher training, can also improve providers' effectiveness. Although training is essential for maintaining high-quality care, it is often needlessly expensive. One potential solution is to provide only the training needed to ensure providers' competence and confidence in their skill. In a clinical skills course in the Philippines, all trainees expressed confidence and demonstrated competence in their ability after seven IUD insertions and removals, so the number of procedures required per provider in training was reduced from 15 to 10 (Rood et al. 1994).

\section{Understand Client Preferences}

Much attention has been devoted to the relative costs of providing a broad range of methal. 2000). 


\section{Providing high-quality care incurs costs, but making the right investments can keep programs from incurring even greater costs or facing unanticipated consequences over the long term due to poor quality of care.}

ods (Mumford et al. 1998). But focusing on only the least expensive methods is not necessarily the most effective strategy. In India, for instance, the focus on sterilization limited women's options for spacing births and seriously impaired the quality of services (Koenig et al. 2000). Combining an awareness of costs with attention to clients' method preferences can improve quality while keeping costs low. A study in Thailand documented not only the high cost of contraceptive implants but also the willingness of contraceptive users to switch to other effective methods. Higher-cost methods could be provided in response to clients' requests, with the cost of the methods offset by user fees or subsidies-although managers would need to ensure that the fee schedule would not exclude disadvantaged clients (Finger 1998; Nanda 2002). Even in resource-poor settings such as sub-Saharan Africa, perceived quality was a major factor in determining clients' willingness to pay for care (Leighton 1995).

\section{Avoid the Costs of Poor-Quality Care}

Providing high-quality care incurs costs, but making the right investments can keep programs from incurring even greater costs or facing unanticipated consequences over the long term due to poor quality of care. If supplies or providers are not available and clients have to return on another day, the program bears the cost of seeing the clients again. Clients may also need more attention if they receive an inappropriate contraceptive method or if they are given substandard counseling and therefore fail to use the method properly. In such instances, the costs to clients also need to be considered.

More serious consequences can also result from poor-quality care. For example, complications after sterilization or IUD insertion have been reported in a number of studies in India (Koenig et al. 2000). One study, conducted in the early 1980s, showed that methodrelated complications were reported for between 29 percent and 46 percent of women using IUDs and for between 12 percent and 23 percent of men and women using sterilization. A more recent report showed that 30 percent of IUD users and 47 percent of women undergoing sterilization in Uttar Pradesh reported complications (Khan et al. 1999). Although these complications may partly reflect high levels of preexisting reproductive tract infections, such existing problems are not entirely to blame: A community-based study in Karnataka, for example, reported that women who had been sterilized were significantly more likely to suffer from vaginitis and painful menstruation (Bhatia et al. 1997).

Poor-quality care clearly imposes costs on clients, programs, and societies. It reduces a program's net benefits and can have long-term consequences such as a decline in demand for services as clients lose confidence in the program. When clients seek services elsewhere, the resulting financial loss can threaten the program's sustainability.

\section{Policy Implications}

Carefully considered investments to enhance the quality of reproductive health programs are necessary and can be cost effective. Quality improvements can save costs to health care services and systems as well as clients. Higherquality services may also attract more clients, increasing a program's efficiency and sustainability. Since each program's service structure and financial constraints differ, managers must decide on the appropriate level of quality given existing and potential resources and the population their programs are meant to serve. The 


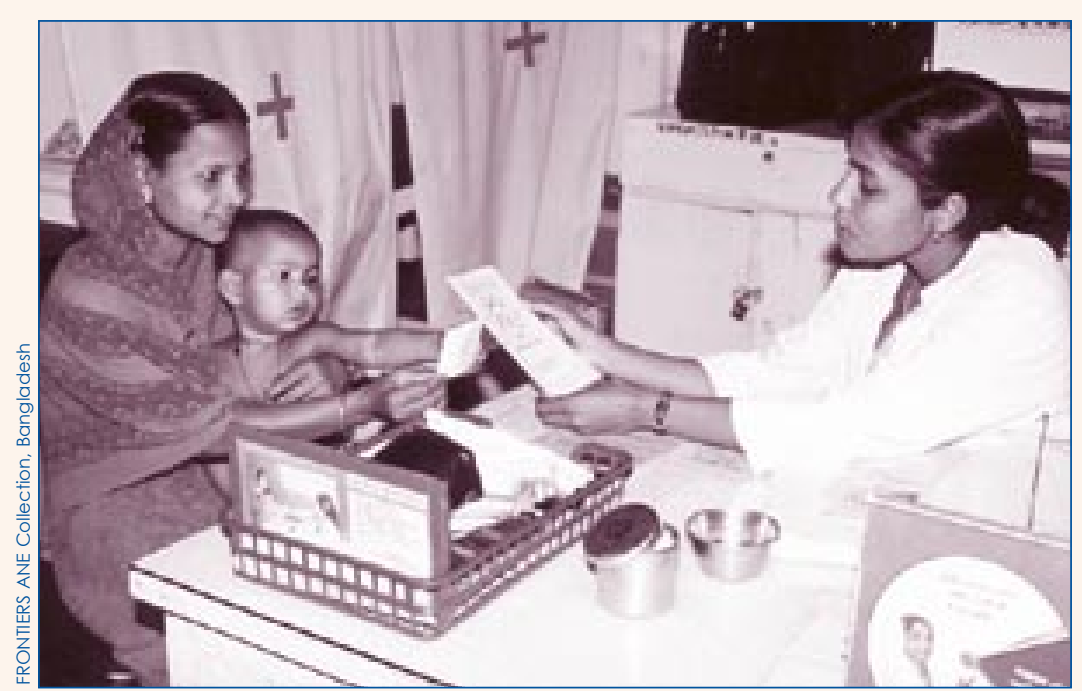

Managers should view the costs of providing high-quality care as investments in the future well-being of both clients and programs.

appropriate balance is best determined in the local context through dialogue among the key stakeholders: policymakers, providers, and clients.

\section{Note}

References are provided in a separate publication that is part of the New Perspectives series and that is available at www. prb.org/newperspectives.

\section{Acknowledgments}

Laura Raney, Stephanie Joyce, and John W. Townsend of the Population Council's Frontiers in Reproductive Health Program (FRONTIERS) prepared this brief in collaboration with Liz C. Creel and Nancy V. Yinger of the Population Reference Bureau (PRB). This paper is based in part on a text originally prepared for FRONTIERS by Rodolfo A. Bulatao.

FRONTIERS gratefully acknowledges the U.S. Agency for International Development (USAID) for supporting this project. This policy brief was funded through FRONTIERS and MEASURE Communication, through Cooperative Agreements No. HRN-A-00-98-00012-00 and HRN-A-00-98-000001-00, respectively.

Special thanks are due to the following reviewers: Michal Avni, Sarah Harbison, Rachel Lucas, Barbara Seligman, and Kellie Stewart of the USAID Bureau for Global Programs, Office of Population; James Foreit, Population Council/FRONTIERS; Cynthia P. Green, Centre for Development and Population Activities; Rick Homan and Barbara Janowitz, Family Health International; Ann Levin, Population Council/HORIZONS and Family Health International; Tim Williams, John Snow, Inc.; and Bill Winfrey, the Futures Group.

Design/Production: Heather Lilley, PRB

Managing Editor: Helena Mickle, PRB

(C) May 2003, Population Reference Bureau
POPULATION REFERENCE BUREAU

\section{MEASURE Communication}

1875 Connecticut Ave., NW, Suite 520, Washington, DC 20009 USA MEASURE Communication

Fax: 202-328-3937

E-mail: measure@prb.org or popref@prb.org

Website: www.measurecommunication.org or www.prb.org

\section{Population Council Trrontiers}

POPULATION COUNCIL

4301 Connecticut Ave., NW, Suite 280, Washington, DC 20008 USA Tel.: 202-237-9400

Fax: 202-237-8410

E-mail: frontiers@pcdc.org

Website: www.popcouncil.org/frontiers/frontiers.html 